\title{
Effects of exogenous indole-3-acetic acid on the growth and cadmium accumulation of lettuce under cadmium stress
}

\author{
Le Liang ${ }^{1}$, Wanjia Tang ${ }^{2}$, Xuemei Peng ${ }^{2}$, Jing Lu² ${ }^{2}$ Han Liu ${ }^{2}$ and Yi Tang ${ }^{1 *}$ \\ ${ }^{1}$ Institute of Pomology and Olericulture, Sichuan Agricultural University, Chengdu, Sichuan, 611130, China \\ ${ }^{2}$ College of Horticulture, Sichuan Agricultural University, Chengdu, Sichuan, 611130, China
}

\begin{abstract}
Indole-3-acetic acid (IAA) plays crucial roles in plant growth and stress tolerance. In present study, the effects of spraying different concentrations $(0,25,50,100$ and $200 \mu \mathrm{mol} / \mathrm{L})$ of IAA on the growth and cadmium (Cd) accumulation in lettuce (Lactuca sativa) were investigated. The lettuce exposed to $\mathrm{Cd}$ exhibited a substantial decline in growth, and the $\mathrm{Cd}$ content of them significantly increased. Spraying exogenous IAA resulted in alleviating the inhibitory of $\mathrm{Cd}$ toxicity to lettuce. The dry weight in shoots of lettuce increased by spraying with IAA compared with the $\mathrm{Cd}$ treatment alone, but the dry weight of roots had no significantly differences. Although exogenous IAA increased the root $\mathrm{Cd}$ content, it significantly reduced shoot $\mathrm{Cd}$ content, indicating its role in $\mathrm{Cd}$ transport. Therefore, spraying IAA effectively alleviated $\mathrm{Cd}$ toxicity and reduced $\mathrm{Cd}$ uptake in the edible parts of lettuce, and the $100 \mu \mathrm{mol} / \mathrm{L}$ IAA was the optimal dose.
\end{abstract}

\section{Introduction}

Lettuce (Lactuca sativa) is a common type of leafy vegetable that is widely cultivated worldwide. Due to limited availability of arable land and the high market demand for vegetables around the world, lettuce is frequently cultivated under unfavourable conditions [1]. Currently, heavy metal contamination of soil is a significant worldwide environmental problem, and the cadmium $(\mathrm{Cd})$ contamination levels are higher than the other metals [2]. The $\mathrm{Cd}$ is toxic trace pollutant for both plants and humans, which enters the soil mainly from human activities and then is transferred to the food chain [3]. Lettuce is a plant species that shows high accumulation of $\mathrm{Cd}$ [4], and has been considered as a $\mathrm{Cd}$ bio-indicator. However, there are no symptoms of dehydration, chlorosis, or necrosis are found on the Cd-contaminated lettuce plants [5].

In recent years, plant growth regulators are gaining increased attention because of its involvement in regulation of abiotic stresses. Indole-3-acetic acid (IAA), as a signal hormone in higher plants, regulates the growth and development of plants, and has a crucial function in stress resistance [6-7]. At present, some studies have demonstrated IAA alleviated Cd-induced toxicity on plants. When $10 \mu \mathrm{mol} / \mathrm{L}$ IAA is sprayed on eggplant seedlings grown in $3 \mathrm{mg} / \mathrm{kg}$ and $9 \mathrm{mg} / \mathrm{kg} \mathrm{Cd}$ contaminated soil, it increases biomass of root and shoot, and decrease the $\mathrm{Cd}$ content of root and shoot [8]. IAA at low doses alleviate the $\mathrm{Cd}$ toxicity by regulating the ascorbate-glutathione cycle as well as activity of other antioxidants in Trigonella seedlings [9]. Agami and Mohamed investigate the resistance mechanism of IAA to cadmium tolerance in wheat seedlings, pre-treatment with IAA enhance the antioxidant defense activities in Cd stressed wheat, and enhance Cd tolerance [10].

In the present investigation, the effect of different concentrations of IAA on the growth and $\mathrm{Cd}$ accumulation of lettuce under $\mathrm{Cd}$ stress were studied. The objective was to determine whether exogenous IAA could mitigate the $\mathrm{Cd}$ toxicity in lettuce by improving the growth and alleviating $\mathrm{Cd}$ accumulation of lettuce.

\section{Materials and methods}

\subsection{Materials}

Seeds of "Glass lettuce" were purchased from the Chengdu seed station. This cultivar shows high purity, good quality, good resistance and suitable growing period (50 d from sowing to harvest), IAA was purchased from Sigma-Aldrich (St. Louis, MO, USA).

\subsection{Experimental design}

The pot experiment was conducted at the Institute of Pomology and Olericulture of Sichuan Agricultural University from February 2017 to June 2017. In February, the uniform size of lettuce seeds were sterilized in $10 \%$ $\mathrm{H}_{2} \mathrm{O}_{2}$ (v/v) for $10 \mathrm{~min}$, and then rinsed with ultrapure water. The sterilized seeds were placed evenly in culture dishes lined with moist filter paper and germinated in an artificial incubator at $20^{\circ} \mathrm{C}$. When the radicle length was $5 \mathrm{~mm}$, the germinated seeds were sown in an enamel tray containing clean sand and grown in an incubator

\footnotetext{
*Corresponding author’s e-mail: 95459425@qq.com
} 
maintained at $23{ }^{\circ} \mathrm{C} / 18{ }^{\circ} \mathrm{C}$ (light/dark) under light intensity of $200 \mu \mathrm{mol} /\left(\mathrm{m}^{-2} \cdot \mathrm{s}^{-1}\right)$ and photoperiod of 14 $\mathrm{h} / 10 \mathrm{~h}$ (light/dark). The $1 / 2$ Hoagland nutrient solution was applied every day.

After $15 \mathrm{~d}$ of culturing, the lettuce plants with four completely unfolded leaves were transplanted into plastic pots $(10 \mathrm{~cm}$ in diameter and height) filled with clean sand, two seedlings per pot. Every three pots were placed in a plastic tray $(8 \mathrm{~cm}$ in height) filled with Hoagland's nutrient solution, and the nutrient solution was replaced at $2 \mathrm{~d}$ intervals. $3 \mathrm{~d}$ after transplanted, the cultivation conditions were changed to the Hoagland's nutrient solution with $10 \mathrm{mg} / \mathrm{L} \mathrm{CdCl} \cdot 2.5 \mathrm{H}_{2} \mathrm{O}$. Lettuce seedlings were cultivated in nutrient solution without $\mathrm{Cd}$ as the control. At the same time, the leaves of the Cd-treated lettuce seedlings were sprayed with different concentrations of IAA solution $(0,25,50,100$, or 200 $\mu \mathrm{mol} / \mathrm{L})$ at 09:00. The control and $\mathrm{Cd}$ treatment alone were sprayed with distilled water. The IAA solutions were applied three times at $2 \mathrm{~d}$ intervals. Each treatment consisted of three pots (on plastic trays) and which was replicated three times. The pots were kept under ambient environmental conditions with natural sunlight and temperature (from March to April). Air temperature ranged between $23 \pm 2.5^{\circ} \mathrm{C}$ (day) and $16 \pm 2.5^{\circ} \mathrm{C}$ (night). Relative humidity varied from 65 to $84 \%$. The lettuce was harvested during the period of organ formation (40 days after transplanted).

\subsection{Determination of Growth parameters and Cd Content}

The whole plant samples $(n=3)$ were rinsed with tap water and washed again with deionized water repeatedly. After drying with absorbent paper, the plant height and root length were measured with a ruler, and stem diameter was measured with vernier caliper. Then, the plants were divided into shoots and roots. The shoots and roots of each treatment were packed separately and dried at $80{ }^{\circ} \mathrm{C}$ to a constant weight. And the dry weight was weighed with an electronic balance. The root/shoot ratio was calculated as root dry weight divided by shoot dry weight. The dried samples were milled and then $0.5 \mathrm{~g}$ powder was digested with $\mathrm{HNO}_{3}-\mathrm{HClO}_{4}(4: 1 \mathrm{v} / \mathrm{v})$. The $\mathrm{Cd}$ content was determined using an iCAP 6300 ICP spectrometer (Thermo Scientific, Waltham, MA, USA) [11]. The translocation factor was calculated as shoot $\mathrm{Cd}$ content divided by root $\mathrm{Cd}$ content.

\subsection{Statistical Analyses}

All data were processed with Excel 2010 software and analysed by means of one-way ANOVA in combination with the least significant difference (LSD) test using SPSS 20.0 statistical software (IBM Corporation, Armonk, NY, USA). Significance was assessed at the 5\% level of probability.

\section{Results}

\subsection{Growth parameters of lettuce}

Cd stress significantly inhibited the growth of lettuce plants. Compared with the control, plant height, stem diameter, and root length were reduced by $7.03 \%(P<$ $0.05), 28.67 \%(P<0.05)$, and $28.32 \%(P<0.05)$, respectively (Table 1). Under Cd stress, the inhibition of growth was alleviated by spraying IAA solution, which increased plant height and stem diameter compared with $\mathrm{Cd}$ treatment alone. Plant height and stem diameter were highest after spraying $100 \mu \mathrm{mol} / \mathrm{L}$ IAA, increased by $10.34 \%(P<0.05)$ and $22.85 \%(P<0.05)$ respectively, compared with $\mathrm{Cd}$ treatment alone. No significant difference in root length and root dry weight was observed between the $\mathrm{Cd}+$ IAA treatments and $\mathrm{Cd}$ treatment alone. Under $\mathrm{Cd}$ stress, the maximum dry weight of shoot was attained when the IAA concentration of $100 \mu \mathrm{mol} / \mathrm{L}$, which was $19.36 \%(P<0.05)$ higher than $\mathrm{Cd}$ treatment alone. With increased in the IAA concentration, the root/shoot ratio of lettuce decreased slightly. The lowest root/shoot ratio was observed after treatment with $100 \mu \mathrm{mol} / \mathrm{L}$ IAA, which was $8.51 \%$ lower than $\mathrm{Cd}$ treatment alone.

Table 1. Effects of exogenous IAA on growth parameters of lettuce plants under Cd stress.

\begin{tabular}{ccccccc}
\hline $\begin{array}{c}\text { Treatment } \\
\text { Cd + IAA }\end{array}$ & $\begin{array}{c}\text { Plant height } \\
(\mathrm{cm})\end{array}$ & $\begin{array}{c}\text { Stem diameter } \\
(\mathrm{mm})\end{array}$ & $\begin{array}{c}\text { Root length } \\
(\mathrm{cm})\end{array}$ & $\begin{array}{c}\text { Shoot biomass } \\
(\mathrm{g} / \mathrm{plant})\end{array}$ & $\begin{array}{c}\text { Root biomass } \\
(\mathrm{g} / \text { plant })\end{array}$ & $\begin{array}{c}\text { Root/shoot } \\
\text { ratio }\end{array}$ \\
\hline Control & $15.08 \pm 0.36 \mathrm{ab}$ & $9.14 \pm 0.21 \mathrm{a}$ & $13.42 \pm 0.43 \mathrm{a}$ & $1.80 \pm 0.07 \mathrm{a}$ & $0.49 \pm 0.02 \mathrm{a}$ & $0.27 \pm 0.00 \mathrm{a}$ \\
1 & $14.02 \pm 0.47 \mathrm{~cd}$ & $6.52 \pm 0.28 \mathrm{~d}$ & $9.62 \pm 0.31 \mathrm{~b}$ & $0.70 \pm 0.03 \mathrm{~d}$ & $0.16 \pm 0.01 \mathrm{~b}$ & $0.24 \pm 0.00 \mathrm{~b}$ \\
2 & $14.48 \pm 0.44 \mathrm{c}$ & $6.72 \pm 0.26 \mathrm{~d}$ & $9.46 \pm 0.29 \mathrm{~b}$ & $0.73 \pm 0.02 \mathrm{~cd}$ & $0.17 \pm 0.01 \mathrm{~b}$ & $0.23 \pm 0.00 \mathrm{~b}$ \\
3 & $14.97 \pm 0.40 \mathrm{~b}$ & $7.10 \pm 0.30 \mathrm{c}$ & $10.00 \pm 0.29 \mathrm{~b}$ & $0.76 \pm 0.04 \mathrm{bc}$ & $0.17 \pm 0.01 \mathrm{~b}$ & $0.22 \pm 0.00 \mathrm{~b}$ \\
4 & $15.47 \pm 0.39 \mathrm{a}$ & $8.01 \pm 0.22 \mathrm{~b}$ & $9.30 \pm 0.14 \mathrm{~b}$ & $0.78 \pm 0.03 \mathrm{~b}$ & $0.17 \pm 0.01 \mathrm{~b}$ & $0.22 \pm 0.00 \mathrm{~b}$ \\
5 & $13.94 \pm 0.48 \mathrm{~d}$ & $7.21 \pm 0.33 \mathrm{c}$ & $9.26 \pm 0.36 \mathrm{~b}$ & $0.73 \pm 0.05 \mathrm{~cd}$ & $0.16 \pm 0.02 \mathrm{~b}$ & $0.23 \pm 0.00 \mathrm{~b}$ \\
\hline
\end{tabular}

Data represent the mean value \pm standard deviation from three replicates. Different letters within same column indicate significant differences at $P<0.05$ significance level between treatments according to the Duncan's multiple range test. The root/shoot ratio was calculated as the biomass in roots divided by the biomass in shoots. The number 1 represents $\mathrm{Cd}+0 \mu \mathrm{mol} / \mathrm{L}$ IAA; The number 2 represents $\mathrm{Cd}+25 \mu \mathrm{mol} / \mathrm{L}$ IAA; The number 3 represents $\mathrm{Cd}+50 \mu \mathrm{mol} / \mathrm{L}$ IAA; The number 4 represents $\mathrm{Cd}+100 \mu \mathrm{mol} / \mathrm{L}$ IAA; The number 5 represents $\mathrm{Cd}+200 \mu \mathrm{mol} / \mathrm{L}$ IAA. 


\subsection{Shoot and Root Cd Contents}

The Cd content of shoots and roots in Cd-treated lettuce significantly increased compared with the control (Table 2). Under Cd stress, application of IAA significantly reduced the $\mathrm{Cd}$ content of shoot in lettuce plants. The lowest $\mathrm{Cd}$ content of shoot was attained in treatment with $100 \mu \mathrm{mol} / \mathrm{L}$ IAA, which was $17.59 \%(P<0.05)$ lower than $\mathrm{Cd}$ treatment alone. The trend for $\mathrm{Cd}$ content of the root was opposite to that for the shoot. The root $\mathrm{Cd}$ content was highest in the presence of $50 \mu \mathrm{mol} / \mathrm{L}$ IAA, which was significantly higher than that of all other treatments. At IAA concentration of 25 and $200 \mu \mathrm{mol} / \mathrm{L}$, no significant difference in root $\mathrm{Cd}$ content was observed between the $\mathrm{Cd}+\mathrm{IAA}$ treatments and $\mathrm{Cd}$ treatment alone. The $\mathrm{Cd}$ translocation factor of the lettuce plants significantly decreased after treatments with IAA compared with the $\mathrm{Cd}$ treatment alone. The minimum $\mathrm{Cd}$ translocation factor was 0.346 in treatment with 50 $\mu \mathrm{mol} / \mathrm{L}$ IAA.

Table 2 Effects of exogenous IAA on Cd content of lettuce under Cd stress.

\begin{tabular}{cccc}
\hline Treatment & $\begin{array}{c}\text { Shoot Cd content } \\
(\mathrm{mg} / \mathrm{kg})\end{array}$ & $\begin{array}{c}\text { Root Cd content } \\
(\mathrm{mg} / \mathrm{kg})\end{array}$ & TF \\
\hline Control & $3.63 \pm 0.03 \mathrm{f}$ & $6.69 \pm 0.054 \mathrm{e}$ & $0.54 \pm 0.00 \mathrm{a}$ \\
$\mathrm{Cd}+0 \mu \mathrm{mol} / \mathrm{L} \mathrm{IAA}$ & $68.29 \pm 0.28 \mathrm{a}$ & $147.34 \pm 4.80 \mathrm{c}$ & $0.46 \pm 0.00 \mathrm{~b}$ \\
$\mathrm{Cd}+25 \mu \mathrm{mol} / \mathrm{L} \mathrm{IAA}$ & $62.16 \pm 0.12 \mathrm{c}$ & $144.10 \pm 1.90 \mathrm{c}$ & $0.43 \pm 0.00 \mathrm{c}$ \\
$\mathrm{Cd}+50 \mu \mathrm{mol} / \mathrm{L} \mathrm{IAA}$ & $61.35 \pm 0.58 \mathrm{~d}$ & $177.37 \pm 0.71 \mathrm{a}$ & $0.35 \pm 0.00 \mathrm{~d}$ \\
$\mathrm{Cd}+100 \mu \mathrm{mol} / \mathrm{L} \mathrm{IAA}$ & $56.28 \pm 0.10 \mathrm{e}$ & $160.62 \pm 1.95 \mathrm{~b}$ & $0.35 \pm 0.00 \mathrm{~d}$ \\
$\mathrm{Cd}+200 \mu \mathrm{mol} / \mathrm{L} \mathrm{IAA}$ & $63.50 \pm 0.32 \mathrm{~b}$ & $150.06 \pm 0.96 \mathrm{c}$ & $0.42 \pm 0.00 \mathrm{c}$ \\
\hline
\end{tabular}

Data represent the mean value \pm standard deviation from three replicates. Different letters within same column indicate significant differences at $P<0.05$ significance level between treatments according to the Duncan's multiple range test. The translocation factor (TF) was calculated as the $\mathrm{Cd}$ content in shoots divided by the $\mathrm{Cd}$ content in roots.

\section{Conclusion}

$\mathrm{Cd}$ stress suppressed the growth and increased the $\mathrm{Cd}$ contention of lettuce plants. Exogenous IAA decreased the $\mathrm{Cd}$ content in shoots of lettuce, alleviated the toxic effect of $\mathrm{Cd}$ on growth. The greatest biomass and the lowest shoot $\mathrm{Cd}$ content, were found in lettuce after foliar application of $100 \mu \mathrm{mol} / \mathrm{L}$ IAA. In summary, IAA alleviated the negative effects of $\mathrm{Cd}$ toxicity on growth, $\mathrm{Cd}$ contention in lettuce plants, which aids in a safe lettuce production in areas with Cd-contaminated soil.

\section{References}

1. Qin, L.F., Guo, S. S., Ai, W. D., Tang, Y. K., Cheng, Q. Y., Chen, G. (2013) Effect of salt stress on growth and physiology in amaranth and lettuce: Implications for bioregenerative life support system. Advances in Space Research, 51: 476-482.

2. Wei, B., Yang, L. (2010) A review of heavy metal contaminations in urban soils, urban road dusts and agricultural soils from China. Microchemical Journal, 94(2): 99-107.

3. Hu, W. Y., Huang, B., Shi, X. Z., Chen, W. P., Zhao, Y. C., Jiao ,W. T. (2013) Accumulation and health risk of heavy metals in a plot-scale vegetable production system in a peri-urban vegetable farm near Nanjing, China.
Ecotoxicology and Environmental Safety, 98: 303-309.

4. Zorrig, W., Khouni, E.L., Ghnaya, T., Davidian, J.C., Abdelly, C., Berthomieu, P. (2013) Lettuce (Lactuca sativa): a species with a high capacity for cadmium (Cd) accumulation and growth stimulation in the presence of low $\mathrm{Cd}$ concentrations. The Journal of Horticultural Science and Biotechnology, 88(6): 783-789.

5. Zorrig, W., Rouached, A., Shahzad, Z., Abdelly, C., Davidian, J. C., Berthomieu, P. (2010) Identification of three relationships linking cadmium accumulation to cadmium tolerance and zinc and citrate accumulation in lettuce. Journal of Plant Physiology, 167: 1239-1247.

6. Agami, R.A. (2016) Pre-soaking in indole-3-acetic acid or spermidine enhances copper tolerance in wheat seedlings. South African Journal of Botany, 104: 167-174.

7. Wang, S. Y., Yuan, S. L., Su, L. T., Lv, A. M., Zhou, P., An, Y. (2017) Aluminum toxicity in alfalfa (Medicago sativa) is alleviated by exogenous foliar IAA inducing reduction of $\mathrm{Al}$ accumulation in cell wall. Environmental and Experimental Botany, 139:11-13.

8. Bashri, G., Prasad, S. M. (2016) Exogenous IAA differentially affects growth, oxidative stress and antioxidants system in $\mathrm{Cd}$ stressed Trigonella foenum-graecum L. seedlings: Toxicity alleviation by up-regulation of ascorbate-glutathione cycle. Ecotoxicology and Environmental Safety, 132: 329-338.

9. Agami, R. A., Mohamed, G. F. (2013) Exogenous treatment with indole-3-acetic acid and salicylic acid alleviates cadmium toxicity in wheat seedlings. Ecotoxicology and Environmental Safety, 94: 164-171. 
10. Singh, S., Prasad, S. M. (2015) IAA alleviates Cd toxicity on growth, photosynthesis and oxidative damages in eggplant seedlings. Plant Growth Regulation, 77: 87-98.

11. Lin, L. J., Liao, M. A., Mei, L. Y., Cheng, J., Liu, J., Luo, L., Liu, Y. (2014) Two ecotypes of hyper-accumulators and accumulators affect cadmium accumulation in cherry seedlings by intercropping. Environmental Progress and Sustainable Energy, 33: 1251-57. 